Анянова Екатерина Сергеевна

кандидат юридических наук, соискатель кафедры международного права Московского государственного института международных отношений (университета), юрисконсульт ООО «Балтторг»

\section{ПРОБЛЕМА ЛЕГИТИМНОСТИ ПОСЛЕДУЮЩИХ ДЕЙСТВИЙ УКРАИНЫ В СВЯЗИ С НАРУШЕНИЕМ ЕЕ ВОЕННЫМИ КОРАБЛЯМИ ГОСУДАРСТВЕННОЙ ГРАНИЦЫ РФ}

\section{Аннотация:}

В статье представлен научно-правовой анализ инициированной заявлением Украины от 31 марта 2019 2. процедуры в Трибунале ООН по морскому праву против России в споре касательно иммунитета трех украинских военных кораблей и моряков на борту. Требования Украины (прекратить уголовный процесс для 24 задержанных украинских членов экипажа, отпустить их и разрешить им вернуться на Украину) в работе изучаются с точки зрения науки международного права. Также исследуется вопрос, есть ли у Трибунала юрисдикция на рассмотрение данного дела и полномочия на предписание временных мер. Отдельно освещена позиция российского судьи Р.А. Колодкина при принятии Трибуналом окончательного решения о временных мерах, он единственный высказался против (за - 19 голосов) при обсуждении освобождения украинских судов, 24 моряков, отказа от других вопросов, осложняющих спор, и подачи начального и последующих отчетов. C позиций международного права активно критикуется позиция Украины.

\section{Ключевые слова:}

Конвенция ООН по морскому праву, Трибунал ООН по морскому праву, военный корабль, юрисдикция, временные меры, свобода судоходства, государственная граница, арест судна.

\section{Anyanova Ekaterina Sergeevna}

PhD in Law, LL.M, Dr. iur., External PhD student International Law Department, Moscow State Institute of International Relations (University) of the Ministry of Foreign Affairs of the Russian Federation, Legal Counsel, Balttorg, 000 (Russia)

\section{ISSUE OF LEGITIMACY OF UKRAINE'S FURTHER ACTIONS RELATED TO CROSSING RUSSIA'S STATE BORDER BY ITS NAVAL FORCES}

\begin{abstract}
Summary:
The study presents a scientific legal analysis of the procedure initiated by Ukraine's claim against Russia in the International Tribunal for the Law of the Sea on 31 March 2019 in the dispute over the immunity of three Ukrainian military vessels and sailors on board. Requests of Ukraine (to stop the criminal process for 24 detained Ukrainian crew members, to release them and to allow them to return to Ukraine) are considered in the paper from the viewpoint of the science of international law. The study reveals whether the Tribunal has juris diction to deal with this case and the competence to prescribe the provisional measures. The emphasis is placed on the position of the Russian judge R.A. Kolodkin in the context of the Tribunal's final decision on the provisional measures. He was the only one who voted against (19 people voted for it) the release of the Ukrain ian vessels, 24 sailors, the refusal of other issues complicating the dispute and the initial and following reports. From the standpoint of the international law, the position of Ukraine is actively criticized.
\end{abstract}

Keywords: UN Convention on the Law of the Sea, International Tribunal for the Law of the Sea, military vessel, jurisdiction, provisional measures, freedom of navigation, state border, ship arrest.

Введение. Статья посвящена правовой оценке задержания военных кораблей Украины при переходе из Черного моря в Азовское вследствие нарушения закона РФ «О Государственной границе РФ» и отдельных положений международного права. Анализируются спор, возникший между Россией и Украиной, о наличии у Международного морского трибунала юрисдикции на рассмотрение данного дела, а также реакция России, отказавшейся участвовать в разбирательстве, и неготовность Украины к переговорам. В работе дан научный анализ комплекса механизмов и процедур мирного урегулирования международных споров как конкретного способа совершенствования международного правопорядка, в том числе такими средствами мирного урегулирования, как непосредственные переговоры (двух-, многосторонние) и международная судебная процедура.

Возможность мирного решения путем международных переговоров между Украиной и Россией в будущем требует более сложных форм и методов регулирования данного процесса, а также его правового осмысления, что делает данную проблему актуальной для науки и обусловливает пристальный научный интерес с точки зрения ее дальнейшей теоретической разработки в отечественной науке международного права.

Научность исследования проявилась в анализе информации, формулировании итоговых положений и выводов на основе фактической источниковой базы дипломатических служб России и Украины, например заявлений представителей МИД Украины, посольства РФ, а также представителей обоих государств в судебном разбирательстве в Трибунале ООН в г. Гамбурге. Характер научной новизны привносится изучением международно-правовых последствий неисполнения 
решений Трибунала стороной в споре и определением правовой компетенции данного органа. Практическая значимость работы определяется возможностью непосредственного использования выводов и заключений в науке и дипломатии, деятельности сотрудников внешнеполитических, внешнеэкономических и правоохранительных ведомств РФ. Предлагаемая тема исследования носит научно-прикладной характер.

Задержание судов в Черном море. Военные корабли Украины «Бердянск», «Никополь» и рейдовый буксир «Яны Капу», направляясь из украинского порта Одессы в украинский порт Бердянска на северном берегу Азовского моря, где они должны были встать на стоянку, 24 ноября 2018 г. были задержаны с обвинением в нарушении государственной границы России, поскольку в Керчь-Еникальском канале применялся разрешительный порядок прохода.

Со ссылкой на временное приостановление Россией права мирного прохода для целей безопасности на основании п. 3 ст. 25 Конвенции ООН по морскому праву 1982 г. делается вывод о нарушении военными кораблями международного права и национального законодательства (ст. 30 Конвенции ООН и ст. 12 (2) Федерального закона от 31 июля 1998 г. № 155-Ф3 «О внутренних морских водах, территориальном море и прилежащей зоне Российской Федерации»). Подобное поведение России обусловлено и исторической перспективой, когда с конца XVIII в. в течение нескольких веков Азовское море находилось на территории одного государства - Российской империи/СССР [1, с. 983]. Таким образом, налицо ограничение права на свободу судоходства, гарантируемого положениями договора между РФ и Украиной о сотрудничестве в использовании Азовского моря и Керченского пролива от 24 декабря 2003 г.

Анализ задержания украинских кораблей [2] демонстрирует игнорирование ими требований РФ, проход кораблей в состоянии боеготовности, невыход на связь, нарушения ст. 30 Закона РФ от 1 апреля 1993 г. № 4730-І «О Государственной границе Российской Федерации». Предупредительная стрельба и даже применение силы основывались на п. 9, 11 Постановления Правительства РФ от 24 фревраля 2010 г. № 80 «Об утверждении Правил применения оружия и боевой техники при охране Государственной границы Российской Федерации, исключительной экономической зоны и континентального шельфа Российской Федерации». Перечисленные нормы права легитимизируют задержание украинских судов с ранеными, которые были направлены на лечение в 1-ю Керченскую городскую больницу. В суде РФ действия Украины были квалифицированы как незаконное пересечение границы украинскими моряками (ч. 3 ст. 322 УК РФ).

Механизм международного правосудия в «европейском измерении». В целях обеспечения стандартов Конвенции Совета Европы о защите прав человека и основных свобод от 4 ноября 1950 г. правительство Украины 11 августа 2018 г. направило заявления в соответствии со ст. 33 (межгосударственные дела) указанной Конвенции против РФ при задержании моряков. 29 ноября 2018 г. на основании правила 39 Регламента ЕСПЧ правительство Украины потребовало от России принять предварительные судебные меры, в частности обеспечить срочную медицинскую помощь раненым морякам, обращаться с ними как с военнопленными в соответствии с Женевской конвенцией от 12 августа 1949 г. об обращении с военнопленными, репатриировать их без промедления. Наличие непосредственного риска непоправимого вреда [3] обусловило срочное предписание временных мер в соответствии со сложившейся практикой суда.

Несмотря на то что требования суда о медобслуживании были исполнены Россией, последующий запрос о переводе моряков на Украину был отклонен, поскольку этот вопрос находится вне юрисдикции суда, а подобное решение не дало бы возможности осуществления правосудия.

Анализ позиции Украины. Анализ ответа России на ноту Украины от 15 марта 2019 г. с требованием к РФ в соответствии со ст. 283 Конвенции ООН показывает, что предложение перейти к обмену мнениями в срок 10 дней демонстрирует готовность России продолжить диалог. Поскольку переговоры с Украиной в соответствии со ст. 283 Конвенции 23 апреля 2019 г. в Гааге сменились в пределах одной недели 31 марта 2019 г. слушаниями перед Трибуналом [4], можно сделать вывод о неготовности Украины к компромиссу. Этот вывод основывается и на том факте, что она отклонила дальнейшие двусторонние переговоры.

Подобные действия представляются необоснованными и чрезмерными. Украина упустила возможность разрешить данный спор в рамках переговоров и прибегнула к спорной судебной процедуре. Неготовность к диалогу подчеркивает справедливость дальнейшего отказа России от продолжения судебного разбирательства и демонстрирует недостатки рассматриваемой процедуры международного правосудия.

Процедура рассмотрения спора в Трибунале по морскому праву. Инициированная заявлением от 31 марта 2019 г. Украины арбитражная процедура в соответствии с приложением VII Конвенции ООН против России в конечном счете затрагивала вопрос иммунитета трех украинских военных кораблей и 24 моряков на борту [5], хотя формально Украина просила всего лишь прекратить уголовный процесс, отпустить их и разрешить им вернуться на Украину [6]. 
Одним из краеугольных моментов рассмотрения данного дела стало применение ст. 298 Конвенции ООН по морскому праву [7]. При ее подписании СССР заявил, что не принимает процедур, влекущих за собой обязательные решения при рассмотрении споров, в том числе касающихся военной деятельности. Аналогичное заявление было сделано заявителем. Это исключение ст. 298 ч. 1 (b) активно использовалось Россией в данном споре [8], с его помощью обосновывалось отсутствие у Трибунала юрисдикции на рассмотрение данного дела и предписание временных мер [9].

Позиция Украины необоснованна, поскольку спор касается не военных действий, а скорее внутренней юрисдикции в контексте обеспечения правопорядка, выразившегося в задержании и аресте военных кораблей и их команд, а следовательно, и требования к Трибуналу признать данные действия России нарушением обязательств в отношении зарубежных военных кораблей и их полного иммунитета в соответствии со ст. 32, 58, 95 и 96 Конвенции ООН и принципами международного обычного права [10].

Этот инцидент логически результируется серьезным усугублением отношений между Россией и Украиной, что может довести до глобального конфликта, учитывая взаимосвязанность ситуации с поддержкой Украины Западом, в частности ООН [11, с. 982].

Анализ особой позиции РФ судьи Р.А. Колодкина при принятии Трибуналом решения продемонстрировал, что, поскольку заявитель сознательно направлял свои военные корабли через воды, контролируемые иностранной береговой охраной и военными силами [12], данный инцидент скорее находился в юрисдикции правоохранительных органов, чем представлял собой военную операцию. Этот судья был единственным, кто высказался против (за - 19 голосов) в вопросах освобождения украинских судов и 24 моряков. Недостаток принудительно насаждаемых государству мер состоит в том, что эффект достигается лишь на время и не гарантирует сотрудничества стран, эффективности и соответствующей реализации [13, с. 108-109].

Неучастие России. Поскольку в вербальной ноте от 30 апреля 2019 г. № 1733/н посольства РФ в ФРГ содержится отказ России от участия в рассмотрении дела, можно сделать вывод, что Россия предпочитает разрешение конфликта путем переговоров. Позиция РФ заключается в том, что Трибунал не обладает юрисдикцией на право решения вооруженных конфликтов [14]. При этом недостатком поведения России является опасность занижения роли международного права.

Правомерным представляется предложение России Украине обратиться к внутринациональным механизмам освобождения из-под стражи под письменные гарантии участия задержанных в досудебных и судебных разбирательствах. Односторонние решения могут привести к ущемлению законных прав и интересов других стран и даже спровоцировать конфликты [15, с. 98-99].

Правовое положение Трибунала при рассмотрении данного дела. Трибунал по морскому праву - сравнительно молодой постоянно действующий международный суд [16, с. 72]. Анализ решения, в котором данный орган отказался классифицировать проход военных кораблей как военную деятельность, характеристика действий России как правоохранительных мероприятий свидетельствуют об аполитичности дела. Трибунал не вмешался в уголовный процесс [17] и посчитал допустимым предписать временные меры с требованием к России освободить суда и 24 задержанных члена экипажей, хотя позволил им вернуться назад. Данные временные меры, частые для международного правосудия, были приняты как разумные гарантии для обеспечения целостности предмета спора. При этом Трибунал на настоящий момент рассмотрел всего девять споров, по результатам чего были предписаны временные меры [18, р. 43], что делает его не слишком авторитетным органом [19, с. 110].

Выводы. Легитимность задержанных судов - это новая проблема, которая в достаточной степени не рассмотрена в российской науке международного права. Она требует проработки и анализа различных аспектов, связанных с международно-правовым режимом обращения в Международный трибунал по морскому праву и исполнения его решений.

Малое количество дел, рассмотренных Трибуналом, обусловило недостаток доверия со стороны России, что подчеркивается ее неучастием не только в данном процессе, но и в рассмотрении вопроса об освобождении судна «Арктик Санрайз» в соответствии со ст. 290 Конвенции ООН по морскому праву 1982 г., когда РФ также не приняла процедуру разбирательства данного дела в Трибунале.

Однако незначительное количество рассмотренных дел не обосновывает решение Трибунала «браться за любую работу», пренебрегая своей специализацией и существующими процессуальными нормами. Несмотря на несоблюдение Россией решения о назначении временных мер, данный отказ легитимен на основании ст. 298 ч. 1 (b) Конвенции ООН по морскому праву 1982 г.

Также можно сделать вывод о необходимости прекратить неоднократные обжалования данных действий в международных судебных инстанциях со стороны Украины, перейти к переговорам с Россией и воспользоваться ее предложением о применении внутринационального механизма для освобождения моряков. Это заключение основывается на неэффективности и недостаточности мер, принимаемых Украиной в одностороннем порядке без достижения компромисса. 
Принцип мирного разрешения международных споров, закрепленный в п. 3 ст. 2 Устава $\mathrm{OOH}$, обязывает государства разрешать международные споры мирными средствами таким образом, чтобы не подвергать угрозе международные мир, безопасность и справедливость. Остается надеяться, что развившиеся в последнее время тенденции на Украине, выразившиеся в отделении части территории с независимым статусом в условиях противоречий с Россией, не перерастут в неразрешимый конфоликт.

\section{Ссылки:}

1. Малышев Д.В. Керченский кризис и статус Азовского моря // Постсоветские исследования. 2019. Т. 2, № 2. С. $982-989$.

2. Case Concerning the Detention of Three Ukrainian Naval Vessels (Ukraine v. Russian Federation) [Электронный ресурс] : Provisional Measures : Case no. 26 // International Tribunal for the Law of the Sea. 2019. May. URL: https://www.itlos.org/cases/list-of-cases/case-no-26 (дата обращения: 03.09.2019).

3. Dissenting Opinion of Judge Kolodkin [Электронный ресурc] // Ibid. URL: https://www.itlos.org/fileadmin/itlos/documents/cases/case_no_26/C26_O25.05_DO_RK.pdf (дата обращения: 03.09.2019).

4. Tribunal to Deliver Its Order on 25 May 2019 at 12 noon. Case Concerning the Detention of Three Ukrainian Naval Vessels (Ukraine v. Russian Federation) [Электронный ресурc] : Provisional Measures : Press Release ITLOS/Press 282. 2019. May 20 // Ibid. URL: https://www.itlos.org/fileadmin/itlos/documents/press_releases_english/PR_282_En.pdf (дата обращения: 03.09.2019).

5. Dissenting Opinion ...

6. Case Concerning the Detention ...

7. Dissenting Opinion ...

8. Case Concerning the Detention ...

9. Dissenting Opinion ...

10. Statement by H.E. Mr. Pavlo Klimkin, Minister for Foreign Affairs of Ukraine, at the 25th Meeting of the Ministerial Council of the OSCE [Электронный ресурc] // Organization for Security and Cooperation in Europe : Official Website. 2018. Dec. 6. URL: https://www.osce.org/whoweare/405560?download=true (дата обращения: 03.09.2019).

11. Малышев Д.В. Указ. соч. С. 982.

12. Dissenting Opinion ...

13. Блищенко И.П. Прецеденты в международном праве. М., 1977. 224 с.

14. Tribunal to Deliver ...

15. Блищенко И.П. Указ. соч. С. 98-99.

16. Абашидзе А.Х., Солнцев А.М., Сюняева М.Д. Консультативное заключение Международного трибунала по морскому праву об ответственности государств за деятельность на морском дне за пределами национальной юрисдикции // Государство и право. 2012. № 7. С. 72-81.

17. ECHR Grants Interim Measure in New Inter-State Case Brought by Ukraine against Russia Concerning Events in the Kerch Strait [Электронный ресурс] : Press Release ECHR $421 / /$ European Court of Human Rights. 2018. 4 Dec. URL: http://www. dirittoue.info/wp-content/uploads/2018/12/ECHR-grants-Rule-39-in-new-inter-State-case-Ukraine-v.-Russiaconcerning-events-in-the-Kerch-Strait.pdf (дата обращения: 03.09.2019).

18. Mensah T. Provisional Measures in the International Tribunal for the Law of the Sea // Zeitschrift für ausländisches öffentliches Recht und Völkerrecht. 2002. Vol. 62. P. 43-54.

19. Толстых В.Л. Международный трибунал по морскому праву: особенности, эволюция и судебная практика // Вестник Новосибирского государственного университета. Сер.: Право. 2011. Т. 7, вып. 2. С. 102-110.

\section{References:}

Abashidze, AKh, Solntsev, AM \& Syunyaeva, MD 2012, 'Advisory Opinion of the International Tribunal for the Law of the Sea on Responsibilities and Obligations of States Sponsoring Persons and Entities with Respect to Activities in the Area', Gosudarstvo i pravo, no. 7, pp. 72-81, (in Russian).

Blishchenko, IP 1977, International Legal Precedents, Moscow, 222 p., (in Russian).

'Case Concerning the Detention of Three Ukrainian Naval Vessels (Ukraine v. Russian Federation): Provisional Measures: Case no. 26' 2019, International Tribunal for the Law of the Sea, May, viewed 03 September 2019, <https://www.itlos.org/cases/list-of-cases/case-no-26>.

'Dissenting Opinion of Judge Kolodkin' 2019, International Tribunal for the Law of the Sea, viewed 03 September 2019, <https://www.itlos.org/fileadmin/itlos/documents/cases/case no 26/C26 O25.05 DO RK.pdf>.

'ECHR Grants Interim Measure in New Inter-State Case Brought by Ukraine against Russia Concerning Events in the Kerch Strait: Press Release ECHR 421' 2018, European Court of Human Rights, 4 December, viewed 03 September 2019, $<$ http://www.dirittoue.info/wp-content/uploads/2018/12/ECHR-grants-Rule-39-in-new-inter-State-case-Ukraine-v.-Russia-concerning-events-in-the-Kerch-Strait.pdf>.

Malyshev, DV 2019, 'Kerch Crisis and the Status of the Azov Sea', Postsovetskie issledovaniya, vol. 2, no. 2, pp. 982-989, (in Russian).

Mensah, T 2002, 'Provisional Measures in the International Tribunal for the Law of the Sea', Zeitschrift für ausländisches öffentliches Recht und Völkerrecht, vol. 62, pp. 43-54.

'Statement by H.E. Mr. Pavlo Klimkin, Minister for Foreign Affairs of Ukraine, at the 25th Meeting of the Ministerial Council of the OSCE' 2018, Official Website of the Organization for Security and Cooperation in Europe, December 6, viewed 03 September 2019, <https://www.osce.org/whoweare/405560?download=true>.

Tolstykh, VL 2011, 'International Tribunal for the Law of the Sea: Features, Evolution and Case Law', Vestnik Novosibirskogo gosudarstvennogo universiteta. Ser.: Pravo, vol. 7, iss. 2, pp. 102-110, (in Russian).

'Tribunal to Deliver Its Order on 25 May 2019 at 12 Noon. Case Concerning the Detention of Three Ukrainian Naval Vessels (Ukraine v. Russian Federation): Provisional Measures: Press Release ITLOS/Press 282' 2019, International Tribunal for the Law of the Sea, May 20, viewed 03 September 2019, <https://www.itlos.org/fileadmin/itlos/documents/press_releases_english/PR_282_En.pdf>. 